\title{
$\delta$-Opioid Receptor Expression in the Ventral Tegmental Area Protects Against Elevated Alcohol Consumption
}

\author{
Elyssa B. Margolis, ${ }^{1}$ Howard L. Fields, ${ }^{1,2,3}$ Gregory 0. Hjelmstad, ${ }^{1,2,3}$ and Jennifer M. Mitchell ${ }^{1,2}$ \\ ${ }^{1}$ Ernest Gallo Clinic and Research Center, University of California, San Francisco, Emeryville, California 94608, ${ }^{2}$ Department of Neurology, University of \\ California, San Francisco, San Francisco, California 94143-0114, and ${ }^{3}$ Wheeler Center for the Neurobiology of Addiction, University of California, San \\ Francisco, San Francisco, California 94143-0114
}

\begin{abstract}
Alcoholism is a complex and debilitating syndrome affecting $\sim 140$ million people worldwide. However, not everyone who consumes ethanol develops abuse, raising the possibility that some individuals have a protective mechanism that inhibits elevated alcohol consumption. We tested the hypothesis that the $\delta$-opioid receptor (DOR) plays such a protective role. Here we show that DOR activity in the ventral tegmental area (VTA) robustly decreases ethanol consumption in rats and that these effects depend on baseline ethanol consumption. Intra-VTA microinjection of the DOR agonist DPDPE decreases drinking, particularly in low-drinking animals. Furthermore, VTA microinjection of the DOR selective antagonist TIPP- $\Psi$ increases drinking in low, but not high, drinkers and this increase is blocked by comicroinjection of the $\mathrm{GABA}_{\mathrm{A}}$ antagonist bicuculline. Using electrophysiological techniques we found that in VTA brain slices from drinking rats DPDPE presynaptically inhibits $\mathrm{GABA}_{\mathrm{A}}$ receptor mediated IPSCs in low drinkers, but not in high drinkers or naive animals, most likely through activation of DORs on GABA terminals. This DOR-mediated inhibition of IPSCs also correlates inversely with

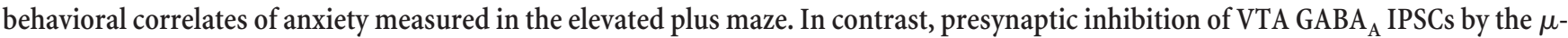
opioid receptor agonist DAMGO is significantly reduced in both high- and low-drinking rats $(<30 \%)$ compared with age-matched nondrinking controls $(>70 \%)$. Together, our findings demonstrate the protective nature of VTA DORs and identify an important new target for therapeutic intervention for alcoholism.
\end{abstract}

Key words: ethanol; ventral tegmental area; $\delta$-opioid; alcoholism; drinking; consumption

\section{Introduction}

The $\delta$-opioid receptor (DOR) plays a protective role in cerebral ischemia, hypoxia, cardiac dysfunction, skeletal muscle damage, peripheral organ survival, and vulnerability to stress (Borlongan et al., 2004; Hebb et al., 2005; Hong et al., 2005; Saitoh et al., 2005; Chao et al., 2007; Förster et al., 2007). Interestingly, CNS expression of DORs is often dynamically induced following physiological challenge (Commons, 2003; Hack et al., 2005; Cahill et al., 2007) and trafficking to the plasma membrane is regulated through a variety of mechanisms, which are dependent on stimulus type and duration (Cahill et al., 2007). Although previous studies have identified a role of the DOR in opioid tolerance and dependence (Gomes et al., 2004; Zhang et al., 2006), and have suggested that DOR activity modulates both food consumption and drug reward (Duvauchelle et al., 1996; Kelley et al., 1996; Ragnauth et al., 1997; Suzuki et al., 1997; Lamonte et al., 2002;

Received Sept. 23, 2008; revised 0ct. 14, 2008; accepted 0ct. 17, 2008.

This work was supported by U. S. Army Awards W81XWH-08-1-0017 and W81XWH-07-1-043; the awarding and administering acquisition office is The U. S. Army Medical Research Acquisition Activity, 820 Chandler Street, Fort Detrick, MD 21702-5014. The content of the information does not necessarily reflect the position or the policy of the Government, and no official endorsement should be inferred. This work was also supported by the State of California for medical research on alcohol and substance abuse through the University of California, San Francisco. We thank Leah Grossman and Joe Driscoll for their technical assistance.

Correspondence should be addressed to Elyssa B. Margolis, Ernest Gallo Clinic and Research Center, 5858 Horton Street, Suite \#200, Emeryville, CA 94608. E-mail: elyssam@gallo.ucsf.edu.

DOI:10.1523/JNEUROSCI.4569-08.2008

Copyright $\odot 2008$ Society for Neuroscience ～0270-6474/08/2812672-10\$15.00/0
Khaimova et al., 2004), to date no one has specifically investigated the possible protective effects of the DOR on drug or ethanol (EtOH) consumption.

The ventral tegmental area (VTA) has been implicated in the motivational actions of opioids (Bozarth and Wise, 1984) and EtOH (McBride et al., 1991): injection of a $\mu$-opioid receptor (MOR) agonist into the VTA is reinforcing (Bals-Kubik et al., 1993; Olmstead and Franklin, 1997; Zangen et al., 2002; Terashvili et al., 2004) while MOR antagonists in the VTA block both opioid and EtOH place preference (Phillips and LePiane, 1980; Bechtholt and Cunningham, 2005). The major reinforcing process in the VTA is thought to be excitation of dopamine (DA) neurons (Schultz, 2007) and MOR agonist-mediated reinforcement in the VTA is thought to be due to inhibition of GABA release onto DA neurons (Johnson and North, 1992). Indeed, MOR agonists in the VTA increase DA levels in multiple VTA projection targets (Spanagel et al., 1992; Devine et al., 1993b; Yoshida et al., 1993) and it has been suggested that endogenous opioid release in the VTA in response to EtOH consumption is accessing the same mechanism to produce reinforcement (Nylander et al., 1994; Bechtholt and Cunningham, 2005).

Although many studies have reported a role for DORs in regulating EtOH intake, no consistent picture of its actions has emerged. DOR knock-out mice consume more EtOH than wild types (Roberts et al., 2001), yet pharmacologically blocking DOR signaling either attenuates EtOH consumption (Lê et al., 1993; 
A

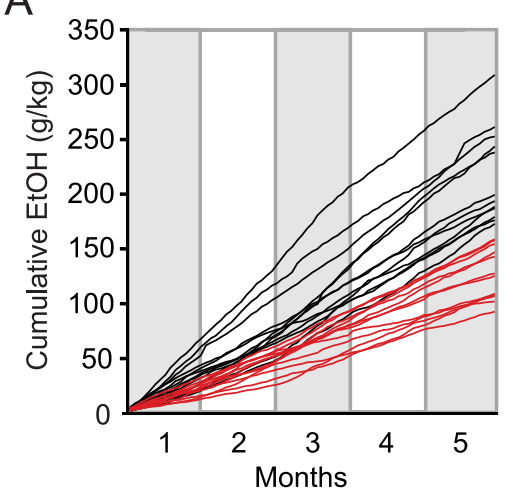

B

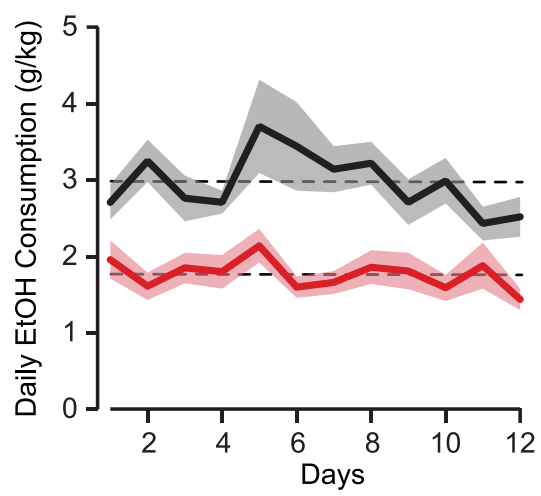

Figure 1. Drinking habits develop and stabilize over months. $\boldsymbol{A}$, Cumulative EtOH consumption for individual high (black; $n=$ 12) and low (red; $n=12$ ) drinking animals over the course of 5 months on a two-bottle free choice, continuous access paradigm. Drinking patterns are clearly established by the end of the fourth month. $\boldsymbol{B}$, Stable EtOH consumption plateau in high and low drinkers over the last 2 weeks before manipulation. Note that there is no crossover between high (black) and low (red) drinking populations. Broken horizontal lines indicate mean consumption over the 12 measurement points and shaded regions \pm SEM for each group.

Froehlich, 1995; Krishnan-Sarin et al., 1995a,b; June et al., 1999; Hyytiä and Kiianmaa, 2001; Ciccocioppo et al., 2002) or has no effect (Hyytiä, 1993; Ingman et al., 2003). The reasons for this variability are not known; however, one possibility is that DOR efficacy changes dynamically during EtOH exposure. To determine whether dynamic regulation of the DOR affects $\mathrm{EtOH}$ intake in chronic drinkers, we studied the effect of DOR ligands on EtOH consumption in high- and low-drinking rats following long-term voluntary EtOH consumption. We performed this investigation in the VTA because opioid signaling in this brain region is sufficient to modulate EtOH reinforcement (Bechtholt and Cunningham, 2005).

\section{Materials and Methods}

Animals. Fifty-three male Lewis rats (Harlan Laboratories) weighing between 275 and $300 \mathrm{~g}$ on arrival were housed individually in a temperature controlled colony room $\left(21^{\circ} \mathrm{C}\right)$ on a $12 \mathrm{~h}$ reversed light/dark cycle (lights off at 10 A.M.). All experiments were performed during the dark portion of the cycle. Rat chow, water, and 10\% EtOH (Gold Shield) were available ad libitum. Experiments were conducted in accordance with the Guide for the Care and Use of Laboratory Animals (National Institutes of Health) and were approved by the Ernest Gallo Clinic and Research Center Committee on Animal Research. Animals were never food or water deprived.

EtOH self-administration. EtOH was administered via a two-bottle continuous access, free-choice paradigm in which one bottle contained $10 \% \mathrm{EtOH} \mathrm{(v/v)} \mathrm{and} \mathrm{the} \mathrm{other} \mathrm{bottle} \mathrm{contained} \mathrm{water.} \mathrm{Sucrose} \mathrm{was} \mathrm{never}$ added to the EtOH solution. The amount of EtOH and water consumed was measured at the same time daily (10 A.M.). Stable selfadministration was achieved in 12-14 weeks (Fig. 1). Experiments began after a stable level of EtOH self-administration was achieved for all animals. Animals were weighed daily. No significant differences or changes in weight were observed between high and low drinkers or between any treatment groups. Bottles were identical and their positions were counterbalanced and rotated daily.

VTA cannulations. Animals were anesthetized and maintained on isoflurane $(0.5 \mathrm{l} / \mathrm{min})$ as needed for the duration of surgery. Animals were placed in a stereotaxic frame and were implanted with bilateral 26-gauge stainless steel chronic guide cannulas (Plastics One) into the VTA (AP, -5.8 ; ML, \pm 0.5 ; DV, -7.0 ) based on the atlas of Paxinos and Watson (1997). Cannulas were secured to the skull with dental cement. At the end of the surgical procedure, animals were treated with penicillin and topical antibiotics. A stainless steel dummy cannula (Plastics One) was inserted into each guide cannula and remained in place when the guide cannulas were not in use. Animals were allowed a 1 week recovery period before behavioral testing.

VTA microinjections. Each injection was made using a $1 \mu \mathrm{l}$ syringe (Hamilton) attached to $20 \mathrm{~cm}$ of PE 50 tubing connected to a 33gauge injection cannula (Plastics One). Microinjections of $0.5 \mu \mathrm{l}$ volumes were given at a rate of $0.5 \mu \mathrm{l} / \mathrm{min}$ using a syringe pump ( $\mathrm{kd}$ Scientific) into each side of the VTA, except for bicuculline injections, where $0.25 \mu \mathrm{l}$ was injected per side. Injection cannulas extended $2 \mathrm{~mm}$ beyond guide cannulas and were left in place for 1 min following microinjections to minimize the backflow of drug solution. In addition to drug microinjections, physiological saline microinjections were made in every rat to measure the effect of the injection manipulation alone on drinking. Drug injections were randomized and counterbalanced. Change in drinking due to drug microinjections was calculated by comparing to both the previous day's consumption ("baseline") and to saline injection. At the conclusion of the experiment, animals were anesthetized with pentobarbital and perfused intracardially through the ascending aorta with $0.1 \mathrm{~m}$ phosphate buffered saline followed by $10 \%$ formalin. Brains were sectioned coronally at $50 \mu \mathrm{m}$, mounted and stained with cresyl violet. Only animals with confirmed injection sites within the VTA were included (see supplemental figure, available at www.jneurosci.org, for placements). No behavioral differences were observed between animals with anterior compared with posterior cannula placements.

Elevated plus-maze. Before electrophysiological slice recordings, animals were run in an Elevated Plus-Maze (Med Associates) for $5 \mathrm{~min}$. The main platform was elevated $75 \mathrm{~cm}$ from the ground and consisted of four arms $(50 \times 10 \mathrm{~cm}$ each $)$ joined by a central platform $(10 \times 10 \mathrm{~cm})$ with floor lines delineating the entrance to each arm. Enclosed arm walls were $40 \mathrm{~cm}$ high. Amount of time in open and closed arms, and number of rearings in open and closed arms were recorded for analysis. Animals began testing when placed in the central hub with their head facing toward a closed arm.

Slice preparation and electrophysiology. Lewis rats were maintained on 2 bottle choice, as described for the behavioral experiments, until their drinking stabilized. Electrophysiological experiments were completed blind to EtOH consumption levels. Recordings were made throughout the VTA. To commence electrophysiological experiments, rats were anesthetized with isoflurane and their brains were removed. Horizontal brain slices (200 $\mu \mathrm{m}$ thick) containing the VTA were prepared using a vibratome (Leica Microsystems). Slices were submerged in artificial CSF solution containing (in mM): $126 \mathrm{NaCl}, 2.5 \mathrm{KCl}, 1.2 \mathrm{MgCl}, 1.4 \mathrm{NaH}_{2} \mathrm{PO}_{4}$, $2.5 \mathrm{CaCl}_{2}, 25 \mathrm{NaHCO}_{3}$, and 11 glucose saturated with $95 \% \mathrm{O}_{2}-5 \% \mathrm{CO}_{2}$ and allowed to recover at $32^{\circ} \mathrm{C}$ for at least $1 \mathrm{~h}$. Individual slices were visualized using a Zeiss Axioskop microscope with differential interference contrast optics and infrared illumination. Whole-cell patch-clamp recordings were made at $32^{\circ} \mathrm{C}$ using $2.5-5 \mathrm{M} \Omega$ pipettes containing (in mм) $128 \mathrm{KCl}, 20 \mathrm{NaCl}, 1 \mathrm{MgCl}_{2}, 1$ EGTA, $0.3 \mathrm{CaCl}_{2}, 10$ HEPES, 2 MgATP, and $0.3 \mathrm{Na}_{3} \mathrm{GTP}$ (pH 7.2, osmolarity adjusted to 275 ), plus $0.1 \%$ biocytin or lucifer yellow to label the recorded neuron. Signals were amplified using a Multiclamp 700B amplifier (Axon Instruments), filtered at $2 \mathrm{kHz}$, and collected at $5 \mathrm{kHz}$ using IGOR Pro (Wavemetric). $I_{\mathrm{h}}$ was measured by voltage clamping cells and stepping from -60 to -40 , $-50,-70,-80,-90,-100$, and $-120 \mathrm{mV}$. Cells were recorded in voltage-clamp mode $(\mathrm{V}=-70 \mathrm{mV})$. Series resistance and input resistance were sampled throughout the experiment with $4 \mathrm{mV}, 200 \mathrm{~ms}$ hyperpolarizing steps. $\mathrm{GABA}_{\mathrm{A}}$ IPSCs were pharmacologically isolated with 6,7-dinitroquinoxaline-2,3(1 H,4H)-dione (DNQX: $10 \mu \mathrm{M}$ ), strychnine $(1 \mu \mathrm{M})$, and sulpiride $(10 \mu \mathrm{M})$. Picrotoxin $(100 \mu \mathrm{M})$ was added at the end of some recordings to confirm the remaining signal was due to $\mathrm{GABA}_{\mathrm{A}}$ receptor activation. Stimulating electrodes were placed $80-250 \mu \mathrm{m}$ away 
from the soma. To measure drug effects on evoked IPSCs, paired pulses (50-ms interval) were delivered once every $10 \mathrm{~s}$. The IPSC amplitude was calculated by comparing a $2 \mathrm{~ms}$ period around the peak to a $2 \mathrm{~ms}$ interval just before stimulation. The paired-pulse ratio (PPR) was calculated by dividing the amplitude of the second IPSC by that of the first, after averaging together 8 consecutive trials. Spontaneous events were detected by searching the smoothed first derivative of the data trace for values that exceeded a set threshold, and these events were confirmed visually. Dose-response experiments were completed in the presence of a MOR antagonist ( $1 \mu \mathrm{M}$ CTAP) to insure the observed effect remained DOR selective at the $10 \mu \mathrm{M}$ dose of DPDPE.

All neurons were identified as $I_{\mathrm{h}}(+)$ or $I_{\mathrm{h}}(-)$. Wherever possible, $I_{\mathrm{h}}(+)$ neurons were immunocytochemically processed for tyrosine hydroxylase (TH) content as a marker for DA neurons (see below). However, since no results differed across any of these cell groups, the data were grouped together for analysis.

Immunocytochemistry. Immediately after electrophysiological recording, slices were fixed in $4 \%$ formaldehyde for $2 \mathrm{~h}$ and then stored at $4^{\circ} \mathrm{C}$ in PBS. Slices were preblocked for $2 \mathrm{~h}$ in PBS plus $0.3 \%(\mathrm{v} / \mathrm{v})$ Tween, $0.2 \%$ $\mathrm{BSA}$ and $5 \%$ normal goat serum and then incubated at $4^{\circ} \mathrm{C}$ with a rabbit anti-tyrosine hydroxylase polyclonal antibody (1:100). The slices were then washed thoroughly in PBS with $0.3 \%$ Tween and $0.2 \%(\mathrm{w} / \mathrm{v})$ BSA before being agitated overnight at $4^{\circ} \mathrm{C}$ with $\mathrm{Cy} 5$ or FITC anti-rabbit secondary antibody (1:100). For cells filled with biocytin, fluorescein (DTAF)-conjugated streptavidin $(3.25 \mu \mathrm{l} / \mathrm{ml})$ was also added during this step. Sections were rinsed and mounted on slides using Bio-Rad Fluoroguard Antifade Reagent mounting media and visualized under a Zeiss LSM 510 META microscope. Primary antibodies were obtained from Chemicon International, secondary antibodies from Jackson ImmunoResearch Laboratories, and all other reagents from Sigma Chemical.

Drugs and doses. For behavioral experiments, DPDPE (10 mM; Sigma), TIPP- $\Psi$ (5 $\mu \mathrm{M}$; NIDA), Bicuculline (1 mM; Sigma), DAMGO (0.2 mм; Sigma), and CTOP (10 mm; Tocris) were prepared in physiological saline for microinjection into the VTA. For electrophysiology, all drugs were applied by bath perfusion. Stock solutions were made and diluted in artificial CSF immediately before application. All chemicals were obtained from Sigma or Tocris except TIPP- $\Psi$, which was acquired from NIDA.

Data analysis. Results are presented as mean \pm SEM where appropriate. For behavioral data, drinking was analyzed using $24 \mathrm{~h}$ time points. Raw drinking data were used for paired Student's $t$ test comparisons probing drug effects on drinking compared with baseline or saline injections, a more conservative comparison than analyzing normalized data. Drinking comparisons and regression analyses were completed in Excel (v.11.4.1; Microsoft). Because TIPP- $\Psi$ induced a long-lasting, robust increase in $\mathrm{EtOH}$ consumption in low-drinking animals (see below), cross-over saline data could not be obtained for three animals that received the TIPP- $\Psi$ injection before saline. Baseline data were substituted for these three animals for benefit of statistical comparison. For electrophysiology, the analyzed data were composed of the $4 \mathrm{~min}$ of baseline just preceding drug application and minutes $4-7$ of drug application. Comparisons across electrophysiology groups were made with one-way ANOVA followed by the Student-Newman-Keuls (SNK) method for multiple comparisons where appropriate using SigmaStat software (SPSS). $p<0.05$ was required for significance in all experiments.

\section{Results}

\section{DOR activation in the VTA attenuates EtOH consumption}

We initially investigated the effects of DOR activation on EtOH consumption by microinjecting DOR selective compounds into the VTA of chronically drinking Lewis rats. The DOR selective agonist DPDPE (10 mM) decreased drinking across all animals compared with drinking the day before treatment ( $n=15, t=$ $2.14, p=0.008$ ) (Fig. 2A). This effect was also evident compared with control saline microinjections in the same rats, and was particularly prominent in low drinkers $(n=7, t=2.45, p=0.02)$ (Fig. $2 B$ ). This DPDPE effect on drinking was only at trend level in high drinkers $(n=8, t=2.36, p=0.059)$ (Fig. $2 B)$. Addition-
A

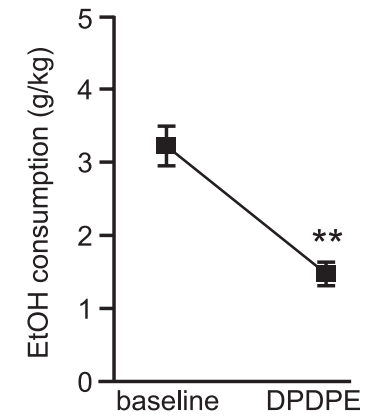

B

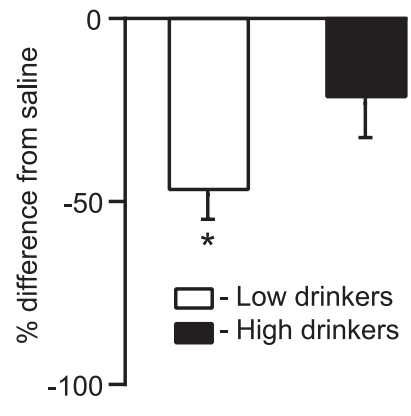

Figure 2. Chronically drinking rats decreased their Et $\mathrm{OH}$ consumption following DOR activation in the VTA. $A$, EtOH drinking decreased across the whole population of rats when the DOR agonist DPDPE (10 mM) was microinjected bilaterally into their VTA compared with the preceding $24 \mathrm{~h}$. $\boldsymbol{B}$, This decrease in drinking was also evident when compared with control saline injection effects and was particularly pronounced in low-drinking animals. ${ }^{*} p<0.05$; ${ }^{* *} p<$ 0.01 .
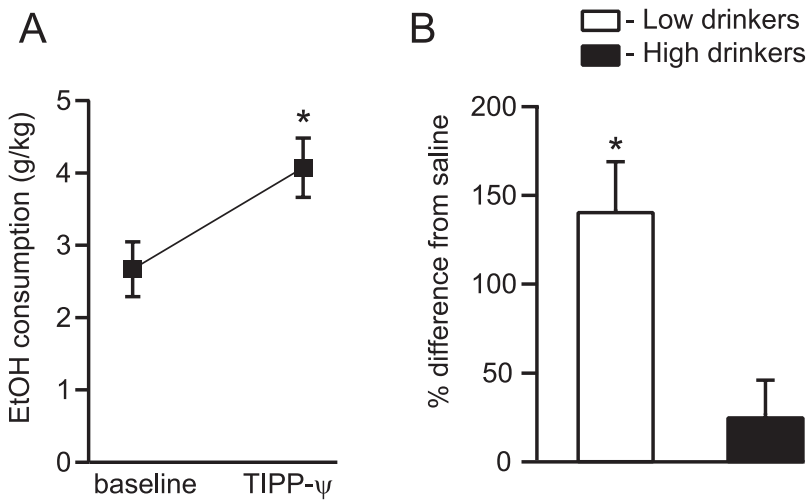

Figure 3. Chronically drinking rats increased their EtOH consumption when DOR signaling was blocked in the VTA. A, Microinjecting the DOR selective antagonist TIPP- $\Psi(5 \mu \mathrm{M})$ into the VTA increased drinking compared with the preceding $24 \mathrm{~h}$ of consumption. $\boldsymbol{B}$, This increase in drinking was also apparent compared with saline injections and was driven by low-drinking animals. ${ }^{*} p<0.05$.

ally, there was an inverse correlation between baseline EtOH consumption and \% baseline drinking following DPDPE administration $(n=15, F=6.35, r=0.57, p=0.02)$, which demonstrated that the lowest drinking animals were the most affected by DPDPE. Consistent with this result, the DOR selective antagonist TIPP- $\Psi(5 \mu \mathrm{M})$ microinjected into the VTA increased drinking across all animals compared with $\mathrm{EtOH}$ consumption the day preceding treatment $(n=14, t=2.16, p=0.006)$ (Fig. $3 A$ ). This was also the case compared with saline injections, and a median split of the data revealed that this effect was again driven by the low drinkers $(n=7, t=2.45, p=0.0002$ for low drinkers vs $n=7, t=2.45, p=0.32$ for high drinkers) (Fig. $3 B$ ). These data suggest that DOR activation by endogenous opioids released in the VTA normally suppresses EtOH intake. Moreover, some animals appear to lack this protective mechanism, resulting in increased $\mathrm{EtOH}$ intake.

\section{DOR activation decreases GABA release in the VTA in chronically drinking animals}

Our behavioral observations indicate that DOR activation in the VTA is interacting with EtOH reinforcement. One possibility is that in low drinkers EtOH is reinforcing at a lower concentration. Since attenuation of $\mathrm{GABA}_{\mathrm{A}}$ signaling in the VTA is reinforcing (Ikemoto et al., 1997) and presynaptic opioid receptor activation 
A
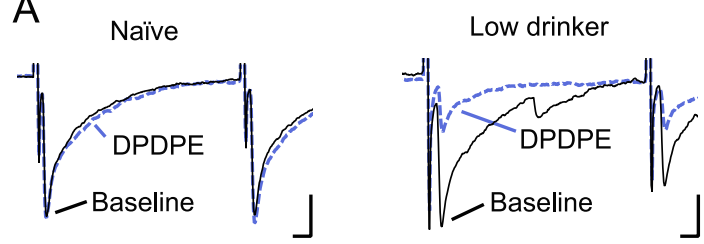

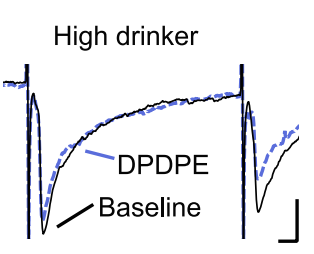

crease in PPR of evoked postsynaptic currents suggests a decrease in the probability of release of neurotransmitter (Manabe et al., 1993). There was a significant increase in the PPR of evoked IPSCs following DPDPE bath application (baseline: $0.85 \pm 0.08$; DPDPE: $1.18 \pm 0.1 ; p=$ $0.03)$. DPDPE also inhibited spontaneous IPSC frequency but not amplitude, across neurons (Fig. 5B,C). Moreover, the change in spontaneous IPSC frequency correlated with the inhibition of evoked IPSCs (slope $=0.75$, intercept $=3.0 ; F=$ 7.17, $r=0.74, p=0.04)$. We also measured miniature IPSCs (mIPSCs) recorded in the presence of tetrodotoxin (TTX; 500 nM) to block possible action potential driven events. DPDPE decreased the frequency of mIPSCs and sIPSCs similarly in neurons from low-drinking animals (Fig. $5 B$ ). Also, as with the spontaneous events, across cells there was no change in the amplitude of mIPSCs with DPDPE (Fig. 5C). We therefore conclude that these DPDPE effects on IPSCs are due to inhibition of GABA release by presynaptic DORs on GABA terminals.

While there was no significant change

can inhibit neurotransmitter release (Williams et al., 2001), we examined whether DOR activation decreases GABA release onto VTA neurons in drinking animals. We measured pharmacologically isolated evoked and spontaneous $\mathrm{GABA}_{\mathrm{A}}$ IPSCs in brain slices from animals with drinking histories similar to those used in the behavioral experiments. We confirmed that the evoked and spontaneous IPSCs were due to $\mathrm{GABA}_{\mathrm{A}}$ receptor activation, as the $\mathrm{GABA}_{\mathrm{A}}$ receptor selective antagonist picrotoxin $(100 \mu \mathrm{M})$ completely blocked both evoked and spontaneous IPSCs $(n=4$, data not shown).

DPDPE (1 $\mu \mathrm{M})$ significantly inhibited both evoked (Fig. 4) and spontaneous (Fig. 5) IPSCs in VTA neurons from drinking animals. In contrast, in age-matched, ethanol-naive, control animals there was no effect of DPDPE on $\mathrm{GABA}_{\mathrm{A}}$ IPSCs (Figs. $4 A, C, D, 5 B, C)$. The DPDPE effect in drinking animals was blocked by the DOR selective antagonist TIPP- $\Psi(1 \mu \mathrm{M})$, indicating that the agonist was acting through the DOR (Fig. 4C). Application of the antagonist alone had no effect on either evoked IPSC amplitude ( $6.8 \pm 9.0 \%$ decrease from baseline, $n=3)$ or spontaneous IPSCs $(8.6 \pm 2.4 \%$ decrease in frequency and $2.6 \pm$ $1.6 \%$ decrease in amplitude, $n=2$ ), suggesting that there is no tonic activation of DOR in this slice preparation. Importantly, for both evoked IPSCs and spontaneous IPSCs there was an inverse correlation between DPDPE induced inhibition and amount of $\mathrm{EtOH}$ consumed, and this relationship was particularly strong for spontaneous IPSC frequency (Fig. 6). We also collected doseresponse data to probe whether elevated $\mathrm{EtOH}$ consumption shifted the $\mathrm{IC}_{50}$ of this DOR-mediated effect or whether the maximal effect was smaller in high-drinking and $\mathrm{EtOH}$ naive animals. We found that in all animal groups $1 \mu \mathrm{M}$ DPDPE was a saturating dose with no apparent shift in the $\mathrm{IC}_{50}$ between groups (Fig. $4 \mathrm{D}$ ).

To confirm that these DOR-mediated effects were mediated by presynaptic receptors located on GABAergic terminals synapsing onto recorded neurons, we examined additional properties of the DPDPE effect in EtOH consuming animals. An in- in the amplitude of spontaneous IPSCs following DPDPE application, a subset of neurons showed a decrease in spontaneous IPSC amplitude. This change was driven by a loss of the largest events (see example in Fig. 5A), which could result from events onto or very close to the soma or from simultaneous release of multiple vesicles. Since these large events persist in the presence of TTX (Fig. $5 D_{\mathrm{i}}$ ), they are not action potential dependent. At some synapses the amplitude distributions of IPSC events are sensitive to changes in the probability of release (Behrends and ten Bruggencate, 1998). Another alternative is that DORs may be expressed on a subset of presynaptic terminals. Consistent with this possibility are the example distributions of mIPSC event amplitudes showing that DPDPE selectively inhibits the frequency of large events in one cell (Fig. $5 D_{\mathrm{i}}$ ) and small events in a different cell (Fig. $5 D_{\text {ii }}$ ).

DOR mediates EtOH consumption through $\mathrm{GABA}_{\mathrm{A}}$ signaling If presynaptic inhibition of GABA release plays a role in our observed intra-VTA DOR modulation of EtOH consumption, then the TIPP- $\Psi$ induced increase in drinking should be blocked by coinjection of a $\mathrm{GABA}_{\mathrm{A}}$ receptor antagonist. In fact, when the $\mathrm{GABA}_{\mathrm{A}}$ receptor antagonist bicuculline $(1 \mathrm{mM})$ was coinjected with TIPP- $\Psi(5 \mu \mathrm{M})$ into the VTA, it completely blocked the TIPP- $\Psi$ induced increase in EtOH consumption in low-drinking animals (Fig. 7). Bicuculline also produced a small overall decrease in drinking across all animals following coadministration $(n=15, p=0.035)$. However, a median split revealed that this effect was carried by high-drinking animals $(n=7, t=2.45, p=$ 0.017 ) (Fig. 7) in whom TIPP- $\Psi$ alone had no significant effect. Furthermore, TIPP- $\Psi$ and bicuculline cotreatment had no effect on EtOH consumption in low-drinking animals $(n=8, t=2.36$, $p=0.79$ ) (Fig. 7). Therefore, VTA GABA neurotransmission plays a critical role in DOR mediated control of EtOH consumption in low-drinking animals. 
DOR modulation of GABA in the VTA correlates with anxiety-like behaviors Because anxiety has been linked to EtOH consumption (Boyd et al., 1989) we also measured behavioral correlates of anxiety using an elevated plus maze prior to electrophysiological experiments. More time spent in the open arms and more open arm rearings suggest an animal is less anxious. We found that the animals that spent more time in the open arms also expressed greater DPDPE-induced inhibition of $\mathrm{GABA}_{\mathrm{A}}$ sIPSC frequency (Fig. $8 \mathrm{~A}$ ). There was also a significant correlation between the number of rearings in the open arms and DPDPE inhibition of sIPSC frequency (Fig. $8 B$ ). These correlations suggest that animals that are less anxious have more functional DORs on GABA terminals in the VTA during chronic drinking, and raise the possibility that activation of these DORs is anxiolytic.

\section{MOR antagonists in the VTA cause a} decrease in $\mathrm{EtOH}$ consumption

Naltrexone's therapeutic effects on drinking have been proposed to be mediated through the MOR (Ghozland et al., 2005; Weerts et al., 2008), and blocking opioid signaling in the VTA diminishes EtOH reinforcement (Bechtholt and Cunningham, 2005). To evaluate the role of VTA MORs in drinking and to compare with our DOR findings, we completed similar behavioral and electrophysiological experiments with MOR ligands. In contrast to DOR, microinjection of the MOR agonist DAMGO $(0.2 \mathrm{mM})$ into the VTA did not affect drinking (Fig. 9A). However, the MOR selective antagonist CTOP (10 mM) significantly decreased drinking (Fig. 9B). In contrast to the DOR antagonist mediated enhancement of ethanol consumption in low drinkers, this MOR antagonist mediated decrease was similar in high- and lowdrinking animals.

\section{MOR agonist effects on GABA release} are diminished in drinking animals Electrophysiologically we found that, compared with EtOH naive animals, DAMGO $(1 \mu \mathrm{M})$ had a relatively small effect on evoked and spontaneous $\mathrm{GABA}_{\mathrm{A}}$ signaling in drinking animals $(27 \pm 10 \%$ in drinkers versus $74 \pm 5 \%$ decrease in evoked $\mathrm{GABA}_{\mathrm{A}}$ amplitude in naive animals) (Fig. $10 A)$. However, there was great variability among these effects (Fig. $10 \mathrm{~B}$ ) and there was no apparent relationship between DAMGO effect and either EtOH consumption or cell type. The DAMGO effects on evoked IPSC amplitude and spontaneous IPSC frequency were correlated within each cell (Fig. $10 \mathrm{~B})$, suggesting a presynaptic site of MOR agonist action on $\mathrm{GABA}_{\mathrm{A}}$ signaling.
$A_{i}$
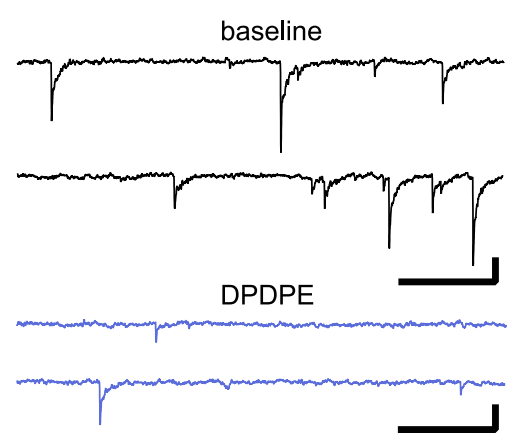

$A_{\text {iii }}$

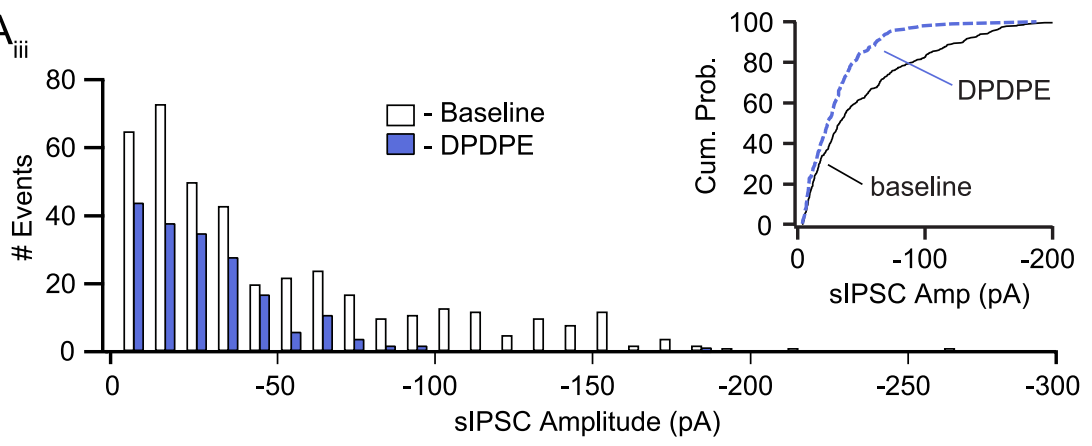

$A_{\mathrm{ii}}$

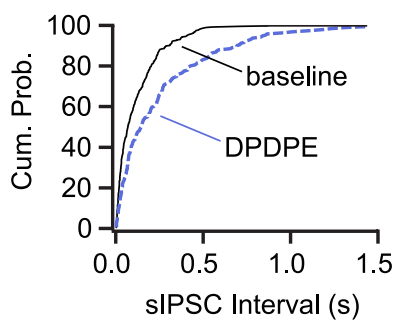

B

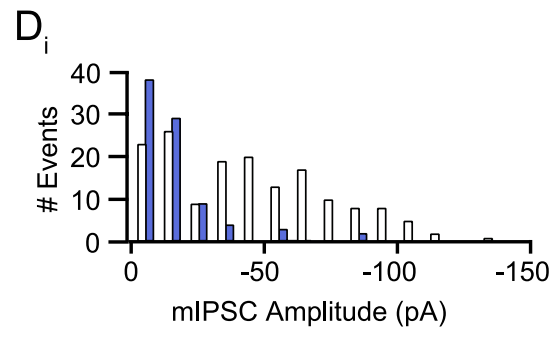

- Low drinkers in TTX

C

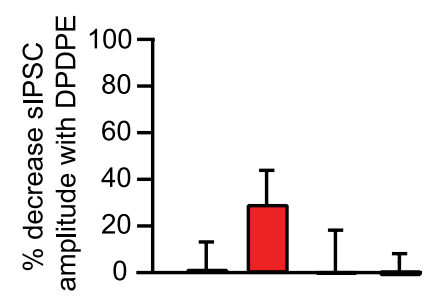

$\mathrm{D}_{\mathrm{ii}}$

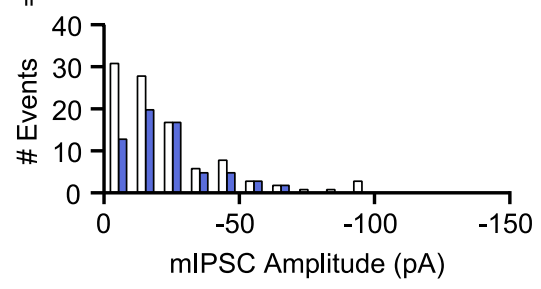

Figure 5. DOR agonists inhibit spontaneous $G_{A B A}$ signaling in the VTA of drinking rats. $A_{i}$, Example traces from the baseline period and DPDPE $(1 \mu \mathrm{M})$ application from a cell from a low-drinking animal showing spontaneous IPSCS. Calibration: $50 \mathrm{pA}, 200$ ms. $A_{i i}$, The cumulative probability plot of event interval from the same neuron shows a rightward shift in interval length in the presence of DPDPE in this case. $A_{i i i}$, A histogram of the event amplitudes shows a decrease in the frequency of the events of all amplitudes with DPDPE. Inset, The cumulative probability plot of the event amplitudes shows a shift to the left with DPDPE indicating a decrease in event amplitudes in this cell. $\boldsymbol{B}$, There was an overall greater DPDPE-induced inhibition of sIPSC frequency in neurons from low-drinking animals $(n=5)$ than in naive $(n=4)$ or high drinkers $(n=7)$, and this effect was also present in neurons from low drinkers when the experiment was conducted in the presence of TTX ( $500 \mathrm{~nm} ; n=5)$. C, There was a nonsignificant trend for DPDPE to decrease the SIPSC amplitude in low-drinking animals. $\boldsymbol{D}$, Example event amplitude histograms from mIPSC experiments collected in the presence of TTX ( $500 \mathrm{nM})$. Very large events persist in the presence of TTX ( $\left.\boldsymbol{D}_{\boldsymbol{i}}\right)$, and DPDPE can either decrease $\left(\boldsymbol{D}_{i}\right)$ or increase $\left(\boldsymbol{D}_{i j}\right)$ the mean amplitude of mIPSCs within a particular neuron.

\section{Baseline $\mathrm{GABA}_{\mathrm{A}}$ signaling following chronic $\mathrm{EtOH}$}

Melis et al. (2002) reported an augmentation of probability of release of GABA onto VTA $I_{\mathrm{h}}(+)$ neurons $24 \mathrm{~h}$ after EtOH injection in mice. We examined our data to see whether such changes persist following chronic EtOH consumption. We found no difference in baseline spontaneous IPSC frequency in $I_{\mathrm{h}}(+)$ neurons between drinking rats $(3.0 \pm 0.6 ; n=23$ neurons) compared with EtOH naive rats $(2.3 \pm 0.4 ; n=11$ 
A

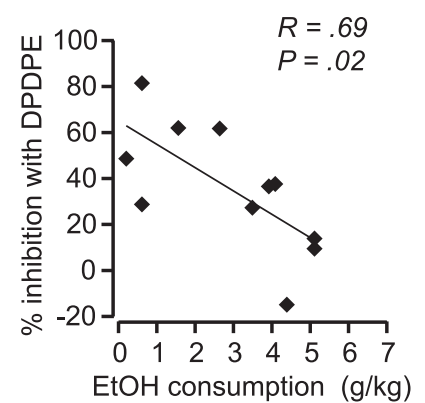

B

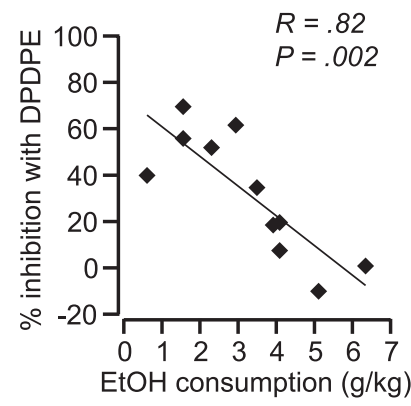

Figure 6. DOR-mediated inhibition of $\mathrm{GABA}_{\mathrm{A}}$ signaling correlates with $\mathrm{EtOH}$ consumption. $A$, The magnitude of the DPDPE inhibition of evoked IPSCs was inversely correlated with EtOH consumption. $\boldsymbol{B}$. There was also an inverse correlation between the extent of the DPDPE inhibition of sIPSC frequency and the amount of EtOH the animal consumed.

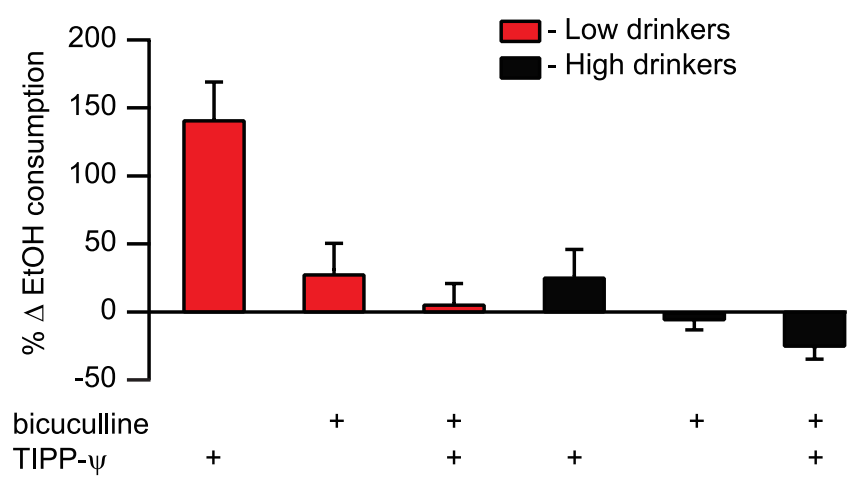

Figure 7. DOR mediates drinking in the VTA through a $\mathrm{GABA}_{A}$ mechanism. Microinjection of the $G A B A_{A}$ antagonist bicuculline $(1 \mathrm{mM})$ into the VTA does not alter drinking when compared with baseline consumption. Coinjection of bicuculline with TIPP- $\Psi(5 \mu \mathrm{M})$ blocks the TIPP- $\Psi$ induced increase in drinking.

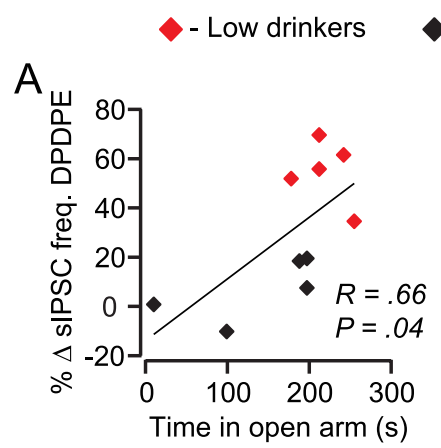

- High drinkers

B

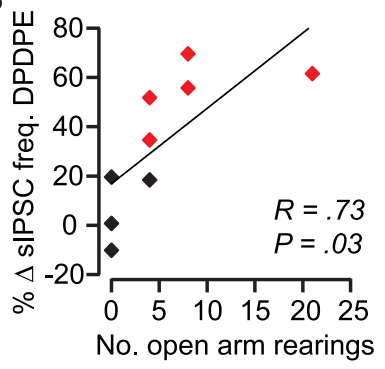

Figure 8. DOR agonist effects on spontaneous IPSC frequency correlate with anxiety measures in drinking animals. Before recordings, animals were tested in the elevated plus maze. The behavioral measures of time in the open arm $(\boldsymbol{A})$ and number of rearings $(\boldsymbol{B})$ correlated with the DOR mediated inhibition of spontaneous $\mathrm{GABA}_{A}$ IPSC frequency.

neurons; $p=0.45)$. Furthermore, the baseline PPR was similar in $I_{\mathrm{h}}(+)$ neurons from drinking $(0.91 \pm 0.10 ; n=21)$ compared with EtOH naive $(0.97 \pm 0.09 ; n=12 ; p=0.70)$ rats. We also observed no difference in the mean amplitude of spontaneous IPSCs between drinking $(32 \pm 4 \mathrm{pA} ; n=23$ neurons) and EtOH naive rats ( $25 \pm 3 \mathrm{pA} ; n=11$ neurons; $p=$ $0.23)$. Therefore, the changes in GABA signaling in the VTA reported in response to acute $\mathrm{EtOH}$ administration appear to not persist following prolonged EtOH consumption.

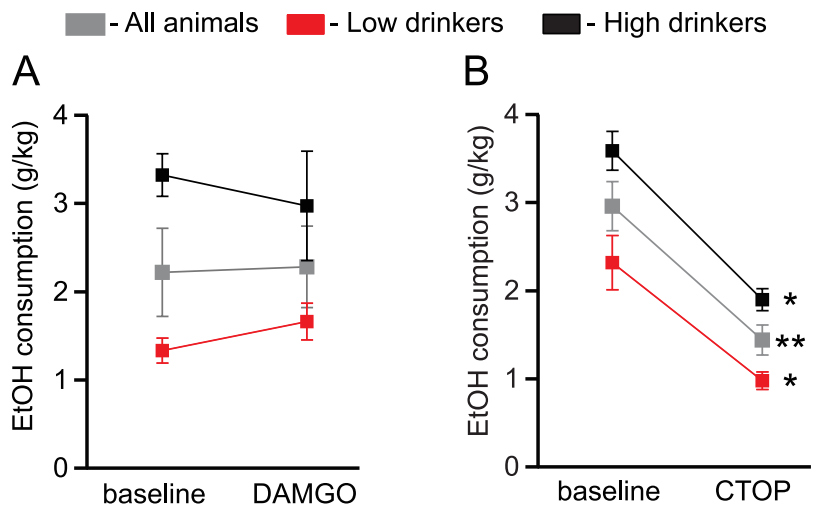

Figure 9. MOR antagonists in the VTA decrease drinking. $A$, The MOR agonist DAMGO $(0.2$ $\mathrm{mm}$ ) microinjected into the VTA does not change EtOH consumption. $\boldsymbol{B}$, The MOR antagonist СTOP (10 mM) microinjected into the VTA decreases EtOH consumption. ${ }^{*} p<0.05$; ${ }^{* *} p<0.01$.

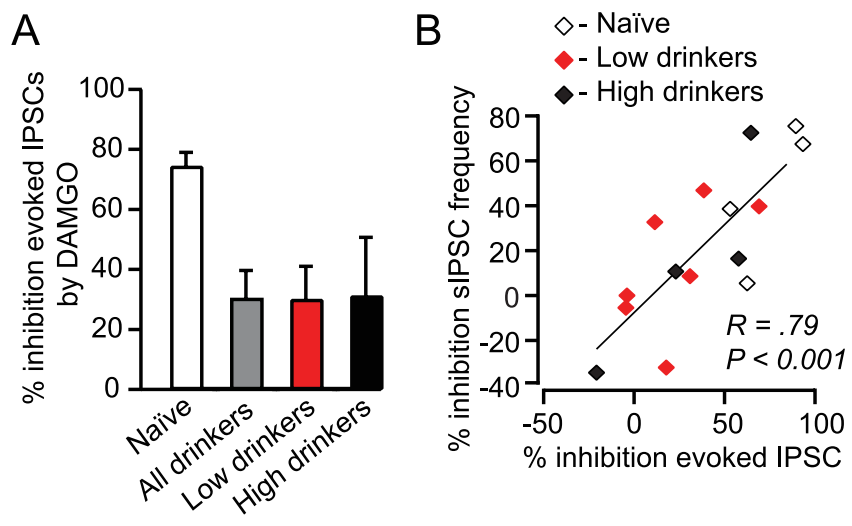

Figure 10. Chronic EtOH consumption decreases presynaptic MOR inhibition at VTA GABA terminals. A, Mean DAMGO (500 nM) effects on evoked IPSC amplitude by treatment group. EtOH naive animals $(n=5)$ showed a greater inhibition of evoked IPSC amplitude with DAMGO than either high $(n=4)$ or low $(n=8)$ drinking animals. $\boldsymbol{B}$, There is a correlation between the effects of DAMGO on evoked IPSC amplitude and spontaneous IPSC frequency but not drinking behavior.

\section{Discussion}

Our results demonstrate that DOR activation in the VTA inhibits $\mathrm{EtOH}$ consumption in actively drinking rats. In low-drinking rats, VTA microinjection of the DOR agonist DPDPE significantly decreases EtOH consumption, while the DOR selective antagonist TIPP- $\Psi$ significantly increases drinking. These effects were not seen in high-drinking rats. Our data implicate presynaptic modulation of GABA release by DOR in these behavioral effects since DPDPE inhibits evoked, spontaneous, and miniature $\mathrm{GABA}_{\mathrm{A}}$ IPSCs in low-drinking animals, but does not change evoked or spontaneous $\mathrm{GABA}_{\mathrm{A}}$ IPSCs in high-drinking or naive animals, and also because the TIPP- $\Psi$ induced increase in $\mathrm{EtOH}$ consumption in low drinkers is blocked by comicroinjection of the $\mathrm{GABA}_{\mathrm{A}}$ antagonist bicuculline.

The emergence of functional DORs following exposure to drugs of abuse and other physiological challenges is a prevalent theme in DOR research. Ultrastructural studies (Cahill et al., 2007) show that in many brain regions DORs have a primarily cytoplasmic location. These cytoplasmic DORs only become available to bind most ligands when they translocate to the cell surface. Such translocation may underlie the emergence of functional DOR on GABA terminals in the periaqueductal gray following $48 \mathrm{~h}$ of exposure to morphine (Hack et al., 2005). Translocation of DORs to the cell membrane also occurs in the nucleus 
accumbens following exposure to psychostimulants (AmbroseLanci et al., 2008). With respect to $\mathrm{EtOH}$, we show here an increase in DOR function on GABA terminals in the VTA following chronic drinking, and this increase in DOR appears to protect against elevated $\mathrm{EtOH}$ consumption. This is consistent with the protective effects of DORs in other systems.

Previous research in EtOH preferring and/or high-drinking rats indicates that a DOR selective antagonist can either have no effect on EtOH consumption (Stromberg et al., 1998; Ingman et al., 2003) or can decrease EtOH consumption (Krishnan-Sarin et al., 1995a,b; June et al., 1999). The present data are consistent with the former findings. However, our current data demonstrate that, in contrast, there is significant DOR action in low-drinking animals. These results highlight the importance of considering individual differences in behavior relative to specific brain functions and offer a possible explanation for the previously reported heterogeneous effects of DOR manipulation on EtOH consumption. Furthermore, since stress and pain also cause increases in functional DORs (Besse et al., 1992; Hao et al., 1998; Ploj et al., 2003), previous experiences may influence DOR ligand modulation of drinking.

Although the anxiolytic properties of DOR selective agonists have been reported previously (Saitoh et al., 2004; Perrine et al., 2006; Jutkiewicz, 2007), the potential electrophysiological mechanisms by which these effects occur have yet to be investigated. Behaviorally, DOR knock-out mice display greater measures of anxiety than matched controls (Filliol et al., 2000), and selective $\delta$ antagonists can attenuate the anxiolytic actions of benzodiazepines (Primeaux et al., 2006). However, to our knowledge, ours is the first examination of an electrophysiological process linking anxiety-like behaviors to specific synaptic actions of DOR activation. We demonstrate that EtOH consuming animals with lower levels of anxiety have greater DOR function on GABA terminals in the VTA, raising the possibility that DOR activation in the VTA is anxiolytic. Furthermore, since less DOR inhibition of GABA release in the VTA correlates with both heightened drinking and higher behavioral anxiety scores, DOR expression in the VTA may be a potential physiological link between anxiety behaviors and EtOH consumption. These data are also intriguing in light of recent results showing an interaction between corticotrophin releasing factor (CRF), a physiological indicator of stress, and EtOH consumption, such that blocking CRF receptor activation decreases EtOH consumption (Heilig and Koob, 2007; Marinelli et al., 2007; Lowery et al., 2008). Additional studies are necessary to investigate the relationship between different types of stress, anxiety, EtOH consumption, and DOR function and to determine the time course of these effects.

Behaviorally, we found that MOR and DOR selective antagonists have opposing effects on EtOH self-administration: intraVTA microinjection of the MOR selective antagonist CTOP decreases consumption while the highly selective DOR antagonist TIPP- $\Psi$ increases consumption. One possible explanation for this difference is that MORs and DORs regulate EtOH consumption through actions at distinct cellular sites within the VTA. Unlike DORs that emerge with EtOH exposure, EtOH downregulates MORs in the VTA (Mendez et al., 2001), in particular diminishing the ability of MOR agonists to decrease $\mathrm{GABA}_{\mathrm{A}}$ signaling. Therefore the dominant effect of MOR activation in drinking animals may be shifted to postsynaptic cell bodies and/or presynaptic glutamate terminals. Microdialysis studies in naive rats show that microinjecting either the MOR agonist DAMGO or the MOR antagonist CTOP into the VTA increases DA levels in the nucleus accumbens (Devine et al., 1993a), sug- gesting a highly complex function of VTA MORs. In naive animals, MORs also modulate glutamate release and postsynaptically inhibit subsets of both DA and non-DA VTA neurons (Cameron et al., 1997; Bonci and Malenka, 1999; Manzoni and Williams, 1999; Margolis et al., 2003, 2005). Thus, MOR modulation of EtOH consumption may be due to a combination of these different synaptic effects in the VTA.

$\mathrm{GABA}_{\mathrm{A}}$ signaling in the VTA participates in a circuit involved in motivation and reinforcement (Ikemoto et al., 1997). Although VTA GABA ${ }_{\mathrm{A}}$ signaling is required for the DOR antagonist mediated increase in EtOH consumption, the downstream consequences of DOR activation are unclear since DOR-mediated inhibition of GABA release is similar onto DA and non-DA neurons. Therefore, in vivo activation of DORs on GABA terminals could disinhibit of all classes of VTA neurons, including glutamate, GABA, and DA neurons (Dahlstroem and Fuxe, 1964; Van Bockstaele and Pickel, 1995; Yamaguchi et al., 2007). Since there are DA-independent outputs of the VTA that can contribute to behavioral reinforcement (Nader and van der Kooy, 1997; Laviolette et al., 2004), it is possible that projecting glutamate or GABA VTA neurons are responsible for the modulation of drinking reported here. DA may also be involved in this modulation, since DA agonists and antagonists alter drinking (Pfeffer and Samson, 1988; Weiss et al., 1990; Rassnick et al., 1992, 1993; Cohen et al., $1998,1999)$. If DA does play a role in DOR-mediated EtOH consumption, our data are consistent with an inverted u-shaped relationship between DA level and reward value. According to this model, animals self administer drugs or consume EtOH to achieve an optimal level of DA release. Therefore, animals with low basal DA or systems that are more resistant to processes that increase DA release tend to self administer larger quantities of drugs or EtOH, while animals with higher basal DA or more responsive DA systems tend to self administer less (Weissenborn et al., 1996; Volkow et al., 1999; Caine et al., 2000; Mattay et al., 2003; Meyer-Lindenberg et al., 2005; Cohen et al., 2007). Our data are consistent with this model in that endogenous opioids released when the animal is drinking should disinhibit DA neurons by activating DORs on GABA terminals, thereby increasing DA release and attenuating EtOH consumption in low-drinking animals. Blocking the DOR with TIPP- $\Psi$ increases GABA release, thereby decreasing DA neural activity in low-drinking animals, which drives these animals to consume more $\mathrm{EtOH}$ to achieve optimal DA release. High-drinking animals, in which these DOR effects are minimal, may drink more because their basal DA levels are lower (Murphy et al., 1983, 1987; Bustamante et al., 2008) or because higher EtOH concentrations are required to increase DA release.

The nonspecific opioid antagonist naltrexone (Revia) is the most widely prescribed FDA approved treatment for alcohol abuse. However, its actions at multiple receptor types are likely a drawback to its use as a therapeutic for alcoholism. Understanding the contribution of each opioid receptor to EtOH consumption could lead to the development of a more effective therapeutic by permitting more selective targeting of the appropriate receptor(s). For example, MOR selective antagonists reduce EtOH intake (Krishnan-Sarin et al., 1998) while KOR selective antagonists can increase EtOH intake (Mitchell et al., 2005; but see Walker and Koob, 2008) in rats. Therefore, antagonizing all opioid receptors simultaneously is not an optimal treatment strategy. We show here that activating, not antagonizing, DORs may be most appropriate for decreasing EtOH consumption. Therefore an improved therapeutic efficacy would likely result from a compound that acts as both a DOR agonist and MOR antagonist. 
Together, our findings demonstrate a protective action of the VTA DOR on alcohol consumption and identify an important new target for therapeutic intervention.

\section{References}

Ambrose-Lanci LM, Peiris NB, Unterwald EM, Van Bockstaele EJ (2008) Cocaine withdrawal-induced trafficking of delta-opioid receptors in rat nucleus accumbens. Brain Res 1210:92-102.

Bals-Kubik R, Ableitner A, Herz A, Shippenberg TS (1993) Neuroanatomical sites mediating the motivational effects of opioids as mapped by the conditioned place preference paradigm in rats. J Pharmacol Exp Ther 264:489-495.

Bechtholt AJ, Cunningham CL (2005) Ethanol-induced conditioned place preference is expressed through a ventral tegmental area dependent mechanism. Behav Neurosci 119:213-223.

Behrends JC, ten Bruggencate G (1998) Changes in quantal size distributions upon experimental variations in the probability of release at striatal inhibitory synapses. J Neurophysiol 79:2999-3011.

Besse D, Weil-Fugazza J, Lombard MC, Butler SH, Besson JM (1992) Monoarthritis induces complex changes in mu-, delta- and kappa-opioid binding sites in the superficial dorsal horn of the rat spinal cord. Eur J Pharmacol 223:123-131.

Bonci A, Malenka RC (1999) Properties and plasticity of excitatory synapses on dopaminergic and GABAergic cells in the ventral tegmental area. J Neurosci 19:3723-3730.

Borlongan CV, Wang Y, Su TP (2004) Delta opioid peptide (D-Ala 2, D-Leu 5) enkephalin: linking hibernation and neuroprotection. Front Biosci 9:3392-3398.

Boyd TL, Callen EJ, House WJ (1989) The effects of post-stress exposure to alcohol upon the development of alcohol consumption in rats. Behav Res Ther 27:35-41.

Bozarth MA, Wise RA (1984) Anatomically distinct opiate receptor fields mediate reward and physical dependence. Science 224:516-517.

Bustamante D, Quintanilla ME, Tampier L, Gonzalez-Lira V, Israel Y, Herrera-Marschitz M (2008) Ethanol induces stronger dopamine release in nucleus accumbens (shell) of alcohol-preferring (bibulous) than in alcohol-avoiding (abstainer) rats. Eur J Pharmacol 591:153-158.

Cahill CM, Holdridge SV, Morinville A (2007) Trafficking of delta-opioid receptors and other G-protein-coupled receptors: implications for pain and analgesia. Trends Pharmacol Sci 28:23-31.

Caine SB, Negus SS, Mello NK (2000) Effects of dopamine D(1-like) and $\mathrm{D}$ (2-like) agonists on cocaine self-administration in rhesus monkeys: rapid assessment of cocaine dose-effect functions. Psychopharmacology (Berl) 148:41-51.

Cameron DL, Wessendorf MW, Williams JT (1997) A subset of ventral tegmental area neurons is inhibited by dopamine, 5 -hydroxytryptamine and opioids. Neuroscience 77:155-166.

Chao D, Bazzy-Asaad A, Balboni G, Xia Y (2007) delta-, but not mu-, opioid receptor stabilizes $\mathrm{K}(+)$ homeostasis by reducing $\mathrm{Ca}(2+)$ influx in the cortex during acute hypoxia. J Cell Physiol 212:60-67.

Ciccocioppo R, Martin-Fardon R, Weiss F (2002) Effect of selective blockade of $\mathrm{mu}(1)$ or delta opioid receptors on reinstatement of alcoholseeking behavior by drug-associated stimuli in rats. Neuropsychopharmacology 27:391-399.

Cohen C, Perrault G, Sanger DJ (1998) Preferential involvement of D3 versus D2 dopamine receptors in the effects of dopamine receptor ligands on oral ethanol self-administration in rats. Psychopharmacology (Berl) 140:478-485.

Cohen C, Perrault G, Sanger DJ (1999) Effects of D1 dopamine receptor agonists on oral ethanol self-administration in rats: comparison with their efficacy to produce grooming and hyperactivity. Psychopharmacology (Berl) 142:102-110.

Cohen MX, Krohn-Grimberghe A, Elger CE, Weber B (2007) Dopamine gene predicts the brain's response to dopaminergic drug. Eur J Neurosci 26:3652-3660.

Commons KG (2003) Translocation of presynaptic delta opioid receptors in the ventrolateral periaqueductal gray after swim stress. J Comp Neurol 464:197-207.

Dahlstroem A, Fuxe K (1964) Evidence for the existence of monoaminecontaining neurons in the central nervous system. I. Demonstration of monoamines in the cell bodies of brain stem neurons. Acta Physiol Scand Suppl 232:1-55.

Devine DP, Leone P, Wise RA (1993a) Mesolimbic dopamine neurotransmission is increased by administration of mu-opioid receptor antagonists. Eur J Pharmacol 243:55-64.

Devine DP, Leone P, Pocock D, Wise RA (1993b) Differential involvement of ventral tegmental mu, delta and kappa opioid receptors in modulation of basal mesolimbic dopamine release: in vivo microdialysis studies. J Pharmacol Exp Ther 266:1236-1246.

Duvauchelle CL, Fleming SM, Kornetsky C (1996) Involvement of deltaand mu-opioid receptors in the potentiation of brain-stimulation reward. Eur J Pharmacol 316:137-143.

Filliol D, Ghozland S, Chluba J, Martin M, Matthes HW, Simonin F, Befort K, Gavériaux-Ruff C, Dierich A, LeMeur M, Valverde O, Maldonado R, Kieffer BL (2000) Mice deficient for delta- and mu-opioid receptors exhibit opposing alterations of emotional responses. Nat Genet 25:195-200.

Förster K, Kuno A, Solenkova N, Felix SB, Krieg T (2007) The delta-opioid receptor agonist DADLE at reperfusion protects the heart through activation of pro-survival kinases via EGF receptor transactivation. Am J Physiol Heart Circ Physiol 293:H1604-H1608.

Froehlich JC (1995) Genetic factors in alcohol self-administration. J Clin Psychiatry 56 Suppl 7:15-23.

Ghozland S, Chu K, Kieffer BL, Roberts AJ (2005) Lack of stimulant and anxiolytic-like effects of ethanol and accelerated development of ethanol dependence in mu-opioid receptor knockout mice. Neuropharmacology 49:493-501.

Gomes I, Gupta A, Filipovska J, Szeto HH, Pintar JE, Devi LA (2004) A role for heterodimerization of mu and delta opiate receptors in enhancing morphine analgesia. Proc Natl Acad Sci U S A 101:5135-5139.

Hack SP, Bagley EE, Chieng BC, Christie MJ (2005) Induction of deltaopioid receptor function in the midbrain after chronic morphine treatment. J Neurosci 25:3192-3198.

Hao JX, Yu W, Xu XJ (1998) Evidence that spinal endogenous opioidergic systems control the expression of chronic pain-related behaviors in spinally injured rats. Exp Brain Res 118:259-268.

Hebb AL, Drolet G, Mendella PD, Roach SP, Gauthier MS, Zacharko RM (2005) Intracerebroventricular D-Pen2, D-Pen5-enkephalin administration soon after stressor imposition influences behavioral responsivity to a subsequent stressor encounter in CD-1 mice. Pharmacol Biochem Behav 82:453-469.

Heilig M, Koob GF (2007) A key role for corticotropin-releasing factor in alcohol dependence. Trends Neurosci 30:399-406.

Hong J, Sigg DC, Coles JA Jr, Oeltgen PR, Harlow HJ, Soule CL, Iaizzo PA (2005) Hibernation induction trigger reduces hypoxic damage of swine skeletal muscle. Muscle Nerve 32:200-207.

Hyytiä P (1993) Involvement of mu-opioid receptors in alcohol drinking by alcohol-preferring AA rats. Pharmacol Biochem Behav 45:697-701.

Hyytiä P, Kiianmaa K (2001) Suppression of ethanol responding by centrally administered CTOP and naltrindole in AA and Wistar rats. Alcohol Clin Exp Res 25:25-33.

Ikemoto S, Murphy JM, McBride WJ (1997) Self-infusion of GABA(A) antagonists directly into the ventral tegmental area and adjacent regions. Behav Neurosci 111:369-380.

Ingman K, Salvadori S, Lazarus L, Korpi ER, Honkanen A (2003) Selective delta-opioid receptor antagonist N,N(CH3)2-Dmt-Tic-OH does not reduce ethanol intake in alcohol-preferring AA rats. Addict Biol 8:173-179.

Johnson SW, North RA (1992) Opioids excite dopamine neurons by hyperpolarization of local interneurons. J Neurosci 12:483-488.

June HL, McCane SR, Zink RW, Portoghese PS, Li TK, Froehlich JC (1999) The delta 2-opioid receptor antagonist naltriben reduces motivated responding for ethanol. Psychopharmacology (Berl) 147:81-89.

Jutkiewicz EM (2007) RB101-mediated protection of endogenous opioids: potential therapeutic utility? CNS Drug Rev 13:192-205.

Kelley AE, Bless EP, Swanson CJ (1996) Investigation of the effects of opiate antagonists infused into the nucleus accumbens on feeding and sucrose drinking in rats. J Pharmacol Exp Ther 278:1499-1507.

Khaimova E, Kandov Y, Israel Y, Cataldo G, Hadjimarkou MM, Bodnar RJ (2004) Opioid receptor subtype antagonists differentially alter GABA agonist-induced feeding elicited from either the nucleus accumbens 
shell or ventral tegmental area regions in rats. Brain Res 1026:284-294.

Krishnan-Sarin S, Portoghese PS, Li TK, Froehlich JC (1995a) The delta 2-opioid receptor antagonist naltriben selectively attenuates alcohol intake in rats bred for alcohol preference. Pharmacol Biochem Behav 52:153-159.

Krishnan-Sarin S, Jing SL, Kurtz DL, Zweifel M, Portoghese PS, Li TK, Froehlich JC (1995b) The delta opioid receptor antagonist naltrindole attenuates both alcohol and saccharin intake in rats selectively bred for alcohol preference. Psychopharmacology (Berl) 120:177-185.

Krishnan-Sarin S, Wand GS, Li XW, Portoghese PS, Froehlich JC (1998) Effect of mu opioid receptor blockade on alcohol intake in rats bred for high alcohol drinking. Pharmacol Biochem Behav 59:627-635.

Lamonte N, Echo JA, Ackerman TF, Christian G, Bodnar RJ (2002) Analysis of opioid receptor subtype antagonist effects upon mu opioid agonistinduced feeding elicited from the ventral tegmental area of rats. Brain Res 929:96-100.

Laviolette SR, Gallegos RA, Henriksen SJ, van der Kooy D (2004) Opiate state controls bi-directional reward signaling via GABAA receptors in the ventral tegmental area. Nat Neurosci 7:160-169.

Lê AD, Poulos CX, Quan B, Chow S (1993) The effects of selective blockade of delta and mu opiate receptors on ethanol consumption by C57BL/6 mice in a restricted access paradigm. Brain Res 630:330-332.

Lowery EG, Sparrow AM, Breese GR, Knapp DJ, Thiele TE (2008) The CRF-1 receptor antagonist, CP-154,526, attenuates stress-induced increases in ethanol consumption by BALB/cJ mice. Alcohol Clin Exp Res 32:240-248.

Manabe T, Wyllie DJ, Perkel DJ, Nicoll RA (1993) Modulation of synaptic transmission and long-term potentiation: effects on paired pulse facilitation and EPSC variance in the CA1 region of the hippocampus. J Neurophysiol 70:1451-1459.

Manzoni OJ, Williams JT (1999) Presynaptic regulation of glutamate release in the ventral tegmental area during morphine withdrawal. J Neurosci 19:6629-6636.

Margolis EB, Hjelmstad GO, Bonci A, Fields HL (2003) Kappa-opioid agonists directly inhibit midbrain dopaminergic neurons. J Neurosci 23:9981-9986.

Margolis EB, Hjelmstad GO, Bonci A, Fields HL (2005) Both kappa and mu opioid agonists inhibit glutamatergic input to ventral tegmental area neurons. J Neurophysiol 93:3086-3093.

Marinelli PW, Funk D, Juzytsch W, Harding S, Rice KC, Shaham Y, Lê AD (2007) The CRF1 receptor antagonist antalarmin attenuates yohimbine-induced increases in operant alcohol self-administration and reinstatement of alcohol seeking in rats. Psychopharmacology (Berl) 195:345-355.

Mattay VS, Goldberg TE, Fera F, Hariri AR, Tessitore A, Egan MF, Kolachana B, Callicott JH, Weinberger DR (2003) Catechol O-methyltransferase val158-met genotype and individual variation in the brain response to amphetamine. Proc Natl Acad Sci U S A 100:6186-6191.

McBride WJ, Murphy JM, Gatto GJ, Levy AD, Lumeng L, Li TK (1991) Serotonin and dopamine systems regulating alcohol intake. Alcohol Alcohol Suppl 1:411-416.

Melis M, Camarini R, Ungless MA, Bonci A (2002) Long-lasting potentiation of GABAergic synapses in dopamine neurons after a single in vivo ethanol exposure. J Neurosci 22:2074-2082.

Mendez M, Leriche M, Calva JC (2001) Acute ethanol administration differentially modulates mu opioid receptors in the rat meso-accumbens and mesocortical pathways. Brain Res Mol Brain Res 94:148-156.

Meyer-Lindenberg A, Kohn PD, Kolachana B, Kippenhan S, McInerney-Leo A, Nussbaum R, Weinberger DR, Berman KF (2005) Midbrain dopamine and prefrontal function in humans: interaction and modulation by COMT genotype. Nat Neurosci 8:594-596.

Mitchell JM, Liang MT, Fields HL (2005) A single injection of the kappa opioid antagonist norbinaltorphimine increases ethanol consumption in rats. Psychopharmacology (Berl) 182:384-392.

Murphy JM, McBride WJ, Lumeng L, Li TK (1983) Monoamine and metabolite levels in CNS regions of the P line of alcohol-preferring rats after acute and chronic ethanol treatment. Pharmacol Biochem Behav 19:849-856.

Murphy JM, McBride WJ, Lumeng L, Li TK (1987) Contents of monoamines in forebrain regions of alcohol-preferring $(\mathrm{P})$ and -nonpreferring (NP) lines of rats. Pharmacol Biochem Behav 26:389-392.
Nader K, van der Kooy D (1997) Deprivation state switches the neurobiological substrates mediating opiate reward in the ventral tegmental area. J Neurosci 17:383-390.

Nylander I, Hyytiä P, Forsander O, Terenius L (1994) Differences between alcohol-preferring (AA) and alcohol-avoiding (ANA) rats in the prodynorphin and proenkephalin systems. Alcohol Clin Exp Res $18: 1272-1279$.

Olmstead MC, Franklin KB (1997) The development of a conditioned place preference to morphine: effects of microinjections into various CNS sites. Behav Neurosci 111:1324-1334.

Paxinos G, Watson C (1997) The rat brain in stereotaxic coordinates, compact, Ed 3. San Diego: Academic.

Perrine SA, Hoshaw BA, Unterwald EM (2006) Delta opioid receptor ligands modulate anxiety-like behaviors in the rat. $\mathrm{Br} \mathrm{J}$ Pharmacol 147:864-872.

Pfeffer AO, Samson HH (1988) Haloperidol and apomorphine effects on ethanol reinforcement in free feeding rats. Pharmacol Biochem Behav 29:343-350.

Phillips AG, LePiane FG (1980) Reinforcing effects of morphine microinjection into the ventral tegmental area. Pharmacol Biochem Behav 12:965-968.

Ploj K, Roman E, Nylander I (2003) Long-term effects of maternal separation on ethanol intake and brain opioid and dopamine receptors in male Wistar rats. Neuroscience 121:787-799.

Primeaux SD, Wilson SP, McDonald AJ, Mascagni F, Wilson MA (2006) The role of delta opioid receptors in the anxiolytic actions of benzodiazepines. Pharmacol Biochem Behav 85:545-554.

Ragnauth A, Ruegg H, Bodnar RJ (1997) Evaluation of opioid receptor subtype antagonist effects in the ventral tegmental area upon food intake under deprivation, glucoprivic and palatable conditions. Brain Res $767: 8-16$.

Rassnick S, Pulvirenti L, Koob GF (1992) Oral ethanol self-administration in rats is reduced by the administration of dopamine and glutamate receptor antagonists into the nucleus accumbens. Psychopharmacology (Berl) 109:92-98.

Rassnick S, Pulvirenti L, Koob GF (1993) SDZ-205,152, a novel dopamine receptor agonist, reduces oral ethanol self-administration in rats. Alcohol 10:127-132.

Roberts AJ, Gold LH, Polis I, McDonald JS, Filliol D, Kieffer BL, Koob GF (2001) Increased ethanol self-administration in delta-opioid receptor knockout mice. Alcohol Clin Exp Res 25:1249-1256.

Saitoh A, Kimura Y, Suzuki T, Kawai K, Nagase H, Kamei J (2004) Potential anxiolytic and antidepressant-like activities of SNC80, a selective deltaopioid agonist, in behavioral models in rodents. J Pharmacol Sci 95:374-380.

Saitoh A, Yoshikawa Y, Onodera K, Kamei J (2005) Role of delta-opioid receptor subtypes in anxiety-related behaviors in the elevated plus-maze in rats. Psychopharmacology (Berl) 182:327-334.

Schultz W (2007) Behavioral dopamine signals. Trends Neurosci 30:203-210.

Spanagel R, Herz A, Shippenberg TS (1992) Opposing tonically active endogenous opioid systems modulate the mesolimbic dopaminergic pathway. Proc Natl Acad Sci U S A 89:2046-2050.

Stromberg MF, Casale M, Volpicelli L, Volpicelli JR, O’Brien CP (1998) A comparison of the effects of the opioid antagonists naltrexone, naltrindole, and beta-funaltrexamine on ethanol consumption in the rat. Alcohol 15:281-289.

Suzuki T, Tsuji M, Ikeda H, Misawa M, Narita M, Tseng LF (1997) Antisense oligodeoxynucleotide to delta opioid receptors blocks cocaineinduced place preference in mice. Life Sci 60:PL 283-288.

Terashvili M, Wu HE, Leitermann RJ, Hung KC, Clithero AD, Schwasinger ET, Tseng LF (2004) Differential conditioned place preference responses to endomorphin-1 and endomorphin-2 microinjected into the posterior nucleus accumbens shell and ventral tegmental area in the rat. J Pharmacol Exp Ther 309:816-824.

Van Bockstaele EJ, Pickel VM (1995) GABA-containing neurons in the ventral tegmental area project to the nucleus accumbens in rat brain. Brain Res 682:215-221.

Volkow ND, Wang GJ, Fowler JS, Logan J, Gatley SJ, Gifford A, Hitzemann R, Ding YS, Pappas N (1999) Prediction of reinforcing responses to psychostimulants in humans by brain dopamine D2 receptor levels. Am J Psychiatry 156:1440-1443. 
Walker BM, Koob GF (2008) Pharmacological evidence for a motivational role of kappa-opioid systems in ethanol dependence. Neuropsychopharmacology 33:643-652.

Weerts EM, Kim YK, Wand GS, Dannals RF, Lee JS, Frost JJ, McCaul ME (2008) Differences in delta- and mu-opioid receptor blockade measured by positron emission tomography in naltrexone-treated recently abstinent alcohol-dependent subjects. Neuropsychopharmacology 33:653-665.

Weiss F, Mitchiner M, Bloom FE, Koob GF (1990) Free-choice responding for ethanol versus water in alcohol preferring $(\mathrm{P})$ and unselected Wistar rats is differentially modified by naloxone, bromocriptine, and methysergide. Psychopharmacology (Berl) 101:178-186.

Weissenborn R, Deroche V, Koob GF, Weiss F (1996) Effects of dopamine agonists and antagonists on cocaine-induced operant responding for a cocaine-associated stimulus. Psychopharmacology (Berl) 126:311-322.
Williams JT, Christie MJ, Manzoni O (2001) Cellular and synaptic adaptations mediating opioid dependence. Physiol Rev 81:299-343.

Yamaguchi T, Sheen W, Morales M (2007) Glutamatergic neurons are present in the rat ventral tegmental area. Eur J Neurosci 25:106-118.

Yoshida M, Yokoo H, Tanaka T, Mizoguchi K, Emoto H, Ishii H, Tanaka M (1993) Facilitatory modulation of mesolimbic dopamine neuronal activity by a mu-opioid agonist and nicotine as examined with in vivo microdialysis. Brain Res 624:277-280.

Zangen A, Ikemoto S, Zadina JE, Wise RA (2002) Rewarding and psychomotor stimulant effects of endomorphin-1: anteroposterior differences within the ventral tegmental area and lack of effect in nucleus accumbens. J Neurosci 22:7225-7233.

Zhang X, Bao L, Guan JS (2006) Role of delivery and trafficking of deltaopioid peptide receptors in opioid analgesia and tolerance. Trends Pharmacol Sci 27:324-329. 